\title{
Pull-out strength of axially loaded steel rods bonded in glulam perpendicular to the grain
}

\section{Journal Article}

Author(s):

Widmann, R.; Steiger, R.; Gehri, E.

Publication date:

2007-10

Permanent link:

https://doi.org/10.3929/ethz-b-000066620

Rights / license:

In Copyright - Non-Commercial Use Permitted

Originally published in:

Materials and Structures 40(8), https://doi.org/10.1617/s11527-006-9214-9 


\title{
Pull-out strength of axially loaded steel rods bonded in glulam perpendicular to the grain
}

\author{
R. Widmann $\cdot$ R. Steiger $\cdot$ E. Gehri
}

Received: 18 April 2006/ Accepted: 23 November 2006/Published online: 23 January 2007

(C) RILEM 2006

\begin{abstract}
A total of 86 pull-out strength tests on glued-in steel rods with metric threads M12, M16 and M20 are reported in this paper. The rods were bonded in glulam made of Norway spruce lamellas perpendicular to the grain by means of an epoxy-type adhesive using the $\mathrm{GSA}^{\circledR}$-system. The slenderness ratios of the rods $\lambda$ calculated from the anchoring lengths $\ell$ with respect to the diameter of the drill hole $d_{\mathrm{h}}\left(\lambda=\ell / d_{\mathrm{h}}\right)$ varied between 7.5 and 12.5. Registered failure loads were considerably higher than design values derived from different existing approaches. The pull-out strength was found to be almost directly proportional to the surface area of the bond line. Based on this an approach to estimate the pullout strength is suggested. Dependence between pull-out strength and anchoring length $\ell$ as well as slenderness ratio $\lambda$ exists, whereas such dependence for the diameter of the rod was not found. The pull-out strength is influenced by the wood density. Compared to rods bonded in parallel to the grain, pull-out strength of rods with same
\end{abstract}

R. Widmann $(\bowtie) \cdot$ R. Steiger

Empa, Swiss Federal Laboratories for Materials

Testing and Research, Wood Laboratory,

Überlandstrasse 129, CH-8600 Dubendorf,

Switzerland

e-mail: robert.widmann@empa.ch

E. Gehri

Prof. em. ETHZ, CH-8803 Ruschlikon, Switzerland diameter and anchoring length set perpendicular to the grain are $20-50 \%$ higher.

Keywords Glued-in rods · Timber · Pull-out strength · Design model

\section{Introduction}

By using glued-in rods stiff, high-capacity connections in timber structures can be realised [1,2], for example rigid beam joints [3, 4] and frame corners [5]. Other possible applications are: strengthening or repairing of timber structural members subjected to high shear stresses or high stresses perpendicular to the grain [6] or simply transferring the load into timber structural elements (e.g., column foundations [2] or anchorages [7]). Since the connection is completely surrounded by the timber it has good fire resistance and provides good design from the aesthetic point of view.

The overall behaviour and the load capacity of glued-in rods depend on the mechanical properties and type of timber, adhesive and rod, and on geometrical aspects like rod length, rod diameter and rod to grain angle.

Based on experimental and theoretical research, several design approaches have been published [8-11]. By comparing these approaches on base of an extended literature review, some 
discrepancy and partly even contradictions between the models, especially regarding the treatment of isolated parameters, were found. On this background, a test program was initiated to study the influence of a selection of these parameters, known or supposed to determine the pull-out strength of single, axially loaded steel rods. Two different kinds of rod to grain angle were experimentally investigated. The results of the first series of tests, which were performed on rods glued in parallel to the grain were reported in [12]. A second series, described in this paper, aimed to examine rods bonded in perpendicular to the grain.

Test specimens consisted of rods with metric screw-threads M12, M16 and M20, bonded with an epoxy-type adhesive into glulam made of Norway spruce (Fig. 1). Two sets of specimens were tested: The first set consisted of rods M12 and M20. A second set with rods M12 and M16 was carried out two years later for verification and additional analyses. The tests were focused to determine the influence of wood density $\rho$, length $\ell$ and diameter $d$ of the rod (or the corresponding drill-hole $d_{\mathrm{h}}$ respectively).

The test program aimed to study practically applicable situations and dimensions and it should enable a comparison with similar test series reported in literature. These objectives could only be reached by permitting certain compromises regarding the test layout. Although for

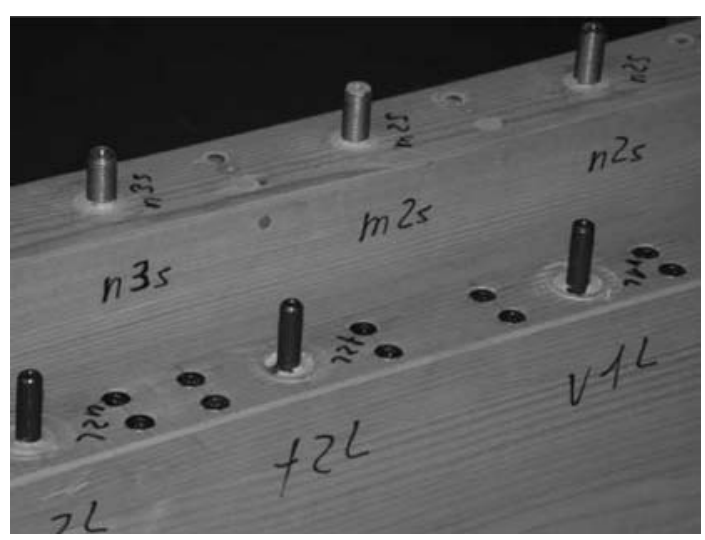

Fig. 1 Steel rods M12 and M16 bonded in glulam perpendicular to the grain example in practice the use of one single rod will not or hardly ever be the normal case, all tests described here were carried out on connections with one single rod, because the examination of such a connection provides a good basis to study the influence of single parameters as they were mentioned before. In practice glued-in rod joints usually are designed in such way that yielding of the steel rod is decisive, thus resulting in a ductile behaviour of the joint at failure level. Contrary to practice the aim of the study was to analyse the influence of timber-related parameters on the pull-out strength of the rods. Therefore rods of high yield limit and strength were chosen in order to provoke shear failure in the timber or the timber-adhesive interface.

Although the test results and the conclusions are specifically valid for the tested system and loading configuration, it is possible to draw some general conclusions about the quantification of the influence of the parameters focused by the study and to compare the test values with existing design models.

\section{Tests}

\subsection{Material properties}

\subsubsection{Timber}

The specimens were cut from glued-laminated timber made of Norway spruce lamellas of $40 \mathrm{~mm}$ thickness. The lamellas were free from any fingerjoints in order to avoid negative influence on the results by this parameter. The glulam members were assembled using a melamine urea formaldehyde (MUF) adhesive. Two pairs of glulam beams were produced from lamellas with clearly distinct distributions of density (Fig. 2), in order to quantify the influence of the wood density on the pull-out strength of the rods. Every single specimen was cut from a beam with a desired density respectively. The wood density was taken as a mean value from the lamellas which were directly affected by the anchoring zone of the rods. As the tests were also aimed at comparing the results with those obtained for rods set 


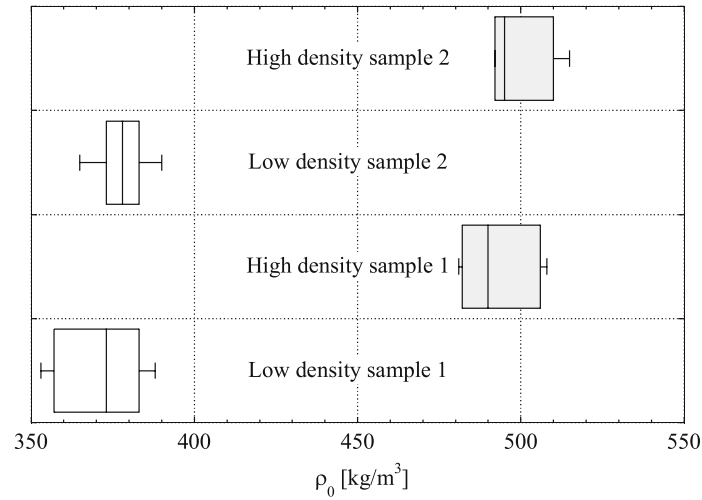

Fig. 2 Box-plots of lamellae's densities used for the production of the glulam beams

parallel to the grain [12], the wood density of the glulam beams was chosen to be within the same range.

\subsubsection{Adhesive}

The tested rods are part of a system called GSA ${ }^{\circledR}$ by n'H (Neue Holzbau AG, Switzerland) [13]. For the $\mathrm{GSA}^{\circledR}$-system a special epoxy-type adhesive, free from any solvent and curing at ambient temperature has been developed by ASTORit AG, Switzerland. This adhesive performs well, as company internal tests showed. Shear strengths up to $35 \mathrm{~N} / \mathrm{mm}^{2}$ were reached between two threaded steel surfaces bonded together. Tests on threaded steel rods bonded in ash established shear failure in timber at a nominal shear strength level between 16 and $18 \mathrm{~N} / \mathrm{mm}^{2}$.

\subsubsection{Steel rods}

In practice, joints with glued-in rods should be designed in such way that steel failure (yielding)

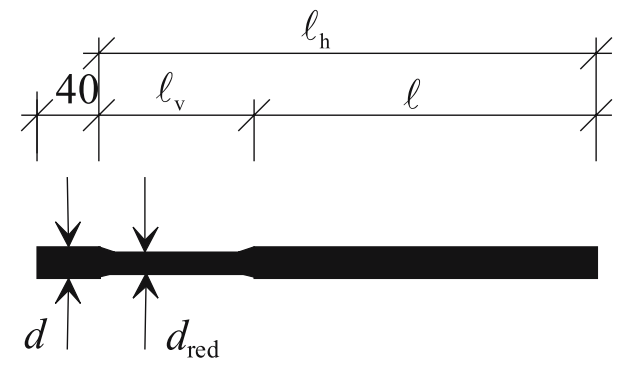

Fig. 3 Geometrical properties of tested rods. Sizes see Table 1 occurs and not wood- or adhesive failure in order to achieve a ductile rather than a brittle rupture. The GSA ${ }^{\circledR}$-system considers this fact by reducing the cross-section of the steel rods within a certain length $\ell_{v}$ (Fig. 3). Removing the rod's thread within the length $\ell_{v}$ also leads to a shift of the anchoring zone to the interior of the specimens. In an investigation by Fabris [14] it has been found that this is an efficient method to prevent early splitting of timber specimens with rods set parallel to grain. In order to enable a comparison of the pull-out strength of rods set parallel to the grain [12] to the results presented in this paper, identical geometrical properties were chosen, even if early splitting of timber is not regarded as being a thread to perpendicular to grain specimens.

The zinc coated steel rods with metric threads M12, M16 and M20 and corresponded to strength grades 8.8 and 10.9 with a characteristic tensile strength $f_{\mathrm{ub}}$ of 800 and $1000 \mathrm{~N} / \mathrm{mm}^{2}$ and a characteristic yield limit $f_{\mathrm{yb}}$ of 640 and $900 \mathrm{~N} / \mathrm{mm}^{2}$, respectively.

\subsection{Specimens, equipment and procedure}

\subsubsection{Assembling of the specimens}

The specimens were assembled in a standing position (Fig. 4) and the holes for the rods with diameters $d_{\mathrm{h}}$ that exceeded the outer (=nominal) diameter of the rods by $2 \mathrm{~mm}$ were drilled using standard spiral bits for wood. The corresponding bond line thickness of $1 \mathrm{~mm}$ is a standard within the $\mathrm{GSA}^{\circledR}$ system and was not varied within our test set-up. The rods were set in the holes and

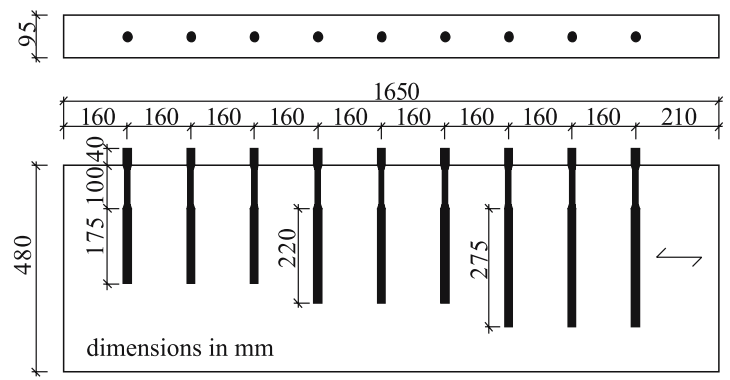

Fig. 4 Example of specimen with rods M20 set perpendicular to the grain 
fixed for assembly in a centred position by spots of superglue. The drill-holes were filled with glue on their entire length $\ell+\ell_{v}$. The adhesive was injected through a small opening ( $5 \mathrm{~mm}$ in width) situated sideways at the bottom of the drill hole until it leaked at the upper end. This procedure guarantied that no bubbles existed within the adhesive layer. For calculations of the shear stress in the anchoring zone, it was assumed that the zone along the length $\ell_{v}$ (which for all specimens was taken to be $5 d$ ) did not contribute to the pullout resistance due to the intended lack of mechanical indentation of rod and adhesive. The length of the effective glued zone corresponded to the length of thread.

Moisture content of the beams was not measured while setting the rods, but target moisture content of the lamellas in the drying kiln was $10 \%$. All specimens were conditioned after setting the rods at a temperature of $20^{\circ} \mathrm{C}$ and at a relative humidity of $65 \%$ for a period of 10 weeks. The moisture content of the specimens was measured immediately before testing them to failure and was found to vary between $11.5 \%$ and $13 \%$.

\subsubsection{Loading configuration}

There are three possible types of loading configurations to carry out pull-out strength tests of rods set perpendicular to the grain reported in literature (Fig. 5). The pull-beam
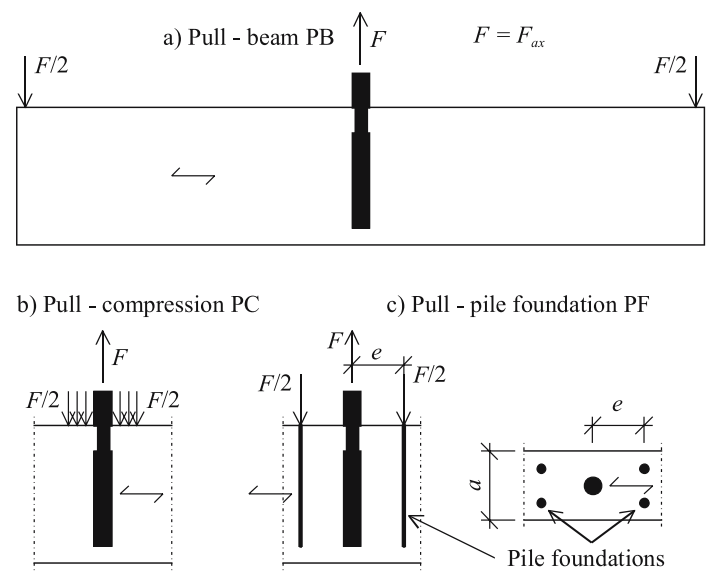

Fig. 5 Possible loading configurations situation PB (Fig. 5a) is closest to practice but inefficient for testing because a large amount of glulam would be required. Additionally the pull-out strength could be influenced by bending stresses in the beam. Testing the specimens in a pull-compression setup PC (Fig. 5b) does not correspond to practical construction details. In addition pull-out strengths might be influenced by local excessive compression stresses perpendicular to the grain in the area of the load application.

The tests therefore were carried out in a pull"pile foundation" PF configuration according to Fig. 5c. This type of loading configuration produces a situation, where the tensile force in the steel rod is balanced by shear stresses in the timber. Crushing of wood due to excessive compression perpendicular to the grain caused by the reaction forces is avoided by four screws (Ø $8 \mathrm{~mm}$ ) with thread over the entire length (M12-series) and four glued-in steel rods M12 (M16- and M20-series) acting like a "pile foundation". These "piles" were set around the rod (Figs. 1 and 5c), with a length equal to that of the tested rod. An optimised (homogeneous) shear zone (more or less uniform distribution of shear stresses) in the section between piles and rod was assumed. The pull-pile foundation configuration prevents also tension failures perpendicular the grain, as were reported in [15] for pull-beam tests. In consequence the actual maximum load carrying capacity of the glued-in rod can be derived directly from the tests.

\subsubsection{Geometric properties of the specimens}

Table 1 summarizes the geometric properties of all specimens tested.

\subsubsection{Equipment and procedure}

All of the tests were carried out load governed on a universal tension-testing machine with a maximal error of the force measurement $<1 \%$. The specimens were ramp loaded up to failure with a rate of loading that resulted in times to failure of 5-7 $\mathrm{min}$ (target time to failure: $300 \mathrm{~s}$ ). 
Table 1 Geometric properties of specimens in reference to Figs. 3 and 5

\begin{tabular}{lccccccc}
\hline Series & $\begin{array}{l}d-d_{\mathrm{h}} \\
(\mathrm{mm})\end{array}$ & $d_{\text {red }}$ & $\ell_{v}$ & $a$ & $e$ & $\ell$ & $\lambda=\ell / d_{\mathrm{h}}$ \\
\hline M12 & $12-14$ & 9.8 & 60 & 55 & 50 & 105 & 7.5 \\
& & & & & & 140 & 10 \\
& & & & & & 175 & 12.5 \\
M16 & $16-18$ & 13.6 & 80 & 75 & 80 & 140 & 7.78 \\
& & & & & & 175 & 9.72 \\
& & & & & & 220 & 12.2 \\
M20 & $20-22$ & 17 & 100 & 95 & 80 & 175 & 7.95 \\
& & & & & & 220 & 10.0 \\
& & & & & & 275 & 12.5 \\
\hline
\end{tabular}

\section{Results and discussion}

\subsection{General}

In general the specimens failed by pull-out of the rods. In comparison to the parallel to grain tests [12] no external signs of failure like cracks or splits in the timber were observed. For verification of the failure mode a number of rods were pulled out completely. The rods were still covered with the adhesive layer along the biggest part of the thread. Some wood fibre was pulled out with the rod but apparently many wood fibres have been stripped-off the adhesive during this final pull-out procedure which limited an evaluation of failure mode. Therefore several specimens were cut off the beam and were opened by carefully splitting them (Fig. 6).

All opened specimens showed big deformations in the wood accompanied by cracks oriented parallel to grain. These cracks were present in both perpendicular and parallel orientation to the rod's axis and indicated failure due to tension stresses perpendicular to grain. Deformations and cracks were concentrated at the lower part of the specimens whereas the upper part, corresponding to the length $\ell_{v}$ of reduced diameter of the rods, did not show visible deformations and/or cracks. This can be seen by the inclination of the adhesive layers in the glulam and the position of the cracks in Fig. 6 which confirmed that the shift of the anchoring zone to the inner part of the timber works as intended.

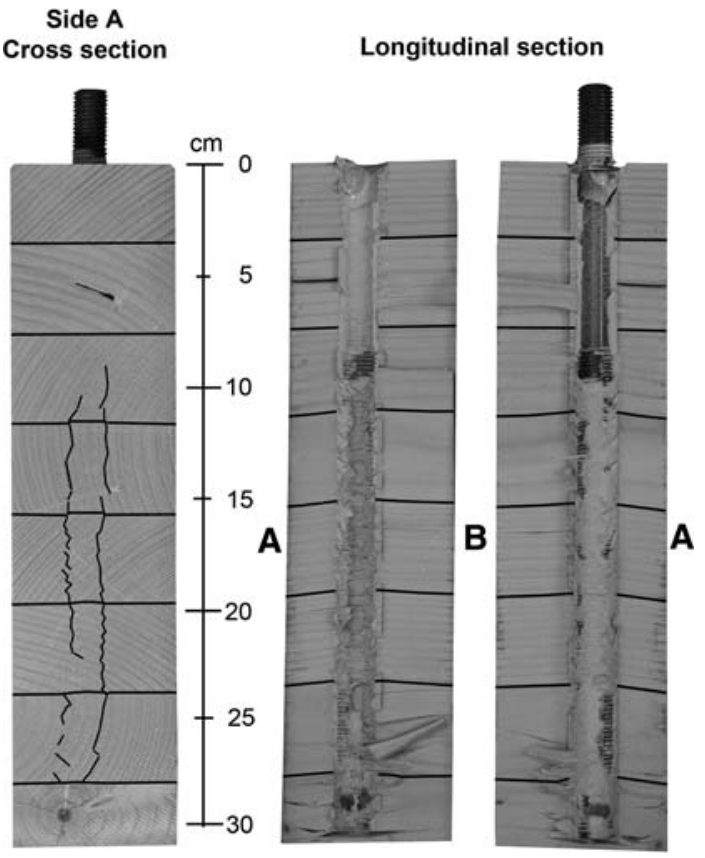

Fig. 6 Example of opened specimen (M16L-220) after failure with highlighted cracks in the cross section and progression of the adhesive layers

Regarding the condition of the wood - adhesive interface different observations were made. In the low-density samples the adhesion to the wood and the mechanical link with the thread of the rods apparently were still intact over almost the entire length $\ell$ of the threaded part of the rod. This was identical with the observations made with the parallel to grain tests [12]. However, some highdensity samples of the M12 series in particular showed also adhesive failure in the interface to the wood in some sections (no wood fibre on adhesive) as well as shear failure in the adhesive layer along the thread of the rod in other sections. For the specimens with more than one visible failure mode it was difficult to distinguish between a primary failure mode and secondary failure mode(s) as a consequence of the initial pull-out or damages due to opening/splitting the specimens after testing. However it can be stated that a combination of wood failures (tension and compression parallel to grain and shear parallel to the axis of the rods) was the prevailing observed failure mode for all samples. 


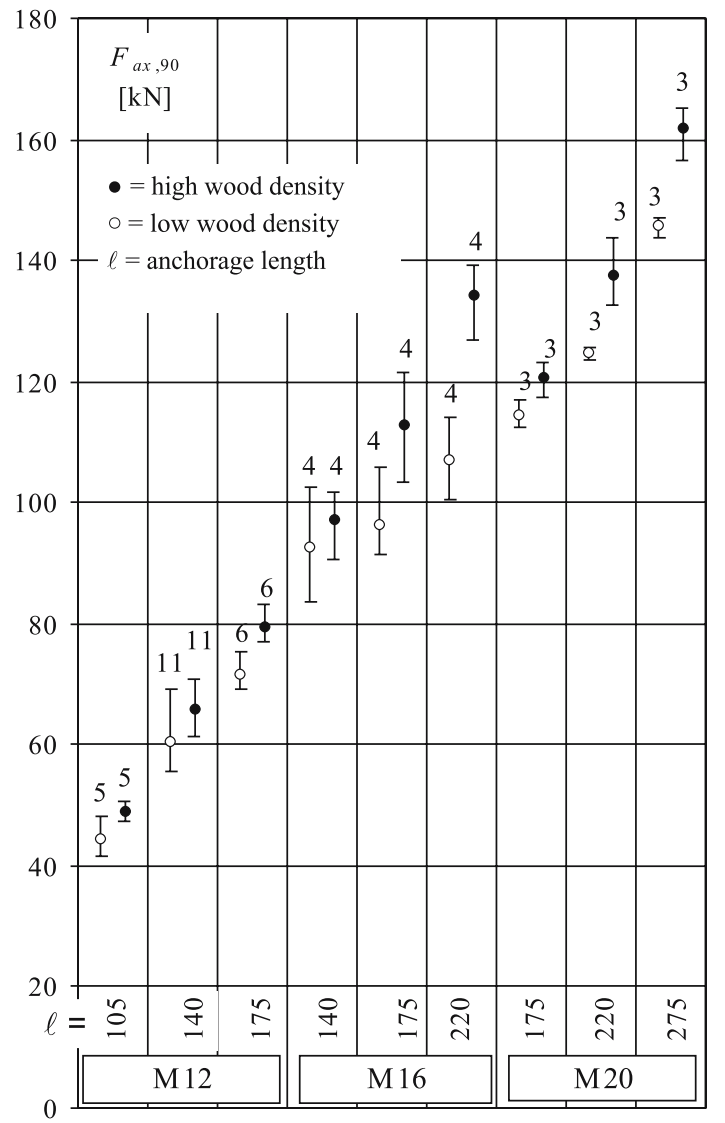

Fig. 7 Mean failure loads with span from minimum to maximum and number of specimens tested per series

A compilation of the test results is given in Fig. 7. In the first set the specimens of series M12 with the longest anchoring length $(\ell=175 \mathrm{~mm})$, failed due to loads that exceeded the steel strength of the rods. The rupture of the rods appeared within the section of the reduced diameter $d_{\text {red }}$ (Fig. 3). The respective ultimate loads are not included in this analysis. In set 2 tests with these dimensions were repeated with the use of higher steel quality (10.9) and rupture in consequence being shifted to the adhesivewood interface.

Compared to rods of the same diameter and anchoring length set parallel to the grain [12] the mean pull-out strengths of rods bonded in glulam perpendicular to the grain were higher. The ratio of the mean ultimate loads perpendicular to grain to the mean ultimate loads parallel to grain $F_{\mathrm{ax}, 90} /$ $F_{\mathrm{ax}, 0}$ was found to vary between 1.17 and 1.54 with a mean of 1.34. In consequence rod-to-grain angle is regarded to be a parameter which should not be neglected when designing joints with glued-in rods.

\subsection{Influence of wood density}

An influence of wood density can only be found if shear failure in timber or in the timber-adhesive interface occurs. These particular failure modes were prevailing for all test as mentioned above. In Fig. 7 it can be seen that for each series the mean pull-out strength of glued-in rods set perpendicular to grain depends on the wood density. Analysis of variance showed that the influence of density was significant at a $5 \%$ level. This was found for an analysis over all series as well as for each single series with the exemption of series M16-140. A significant influence of density contradicts the results in [16]. It can be assumed that the effect of shifting the anchorage zone in our study compared to no shift in [16] is responsible for the different findings.

The mean ultimate loads of high-density samples were in average about $11 \%$ higher than those of the low-density samples. The difference was inconsistent, however, and varied from series to series, e.g. high difference $(+25 \%)$ between M16220 high and low density and small difference $(+5 \%)$ between M16-140 high and low. It also turned out that the influence of density on the pull-out strength increased with an increasing glued length $\ell$ within the series M16 and M20 whereas the density influence remained constant within the M12 series. The failure mode analyse on opened specimens was not able to explain the inconstancy.

The mean values of calculated exponents $c_{i}$ from $\left(F_{1} / F_{2}\right)=\left(\rho_{1} / \rho_{2}\right)^{c}$ comparing the high-density glulam sample $\left(F_{1}, \rho_{1}\right)$ with the low-density sample $\left(F_{2}, \rho_{2}\right)$ is $c_{\text {mean,90 }}=0.37$ with a range of $c_{\min }=0.18$ and $c_{\max }=0.82$. These results partly correspond to those presented in [16] but are of bigger scatter. With regard to this scatter of data, it is proposed to neglect the density influence for rods set perpendicular to the grain in design models or to take density into account only carefully, e.g. by using an exponent of $c_{90}=0.25$. 
3.3 Influence of geometric properties of the glued zone

When analysing the pull-out strength with respect to the geometrical properties of the glued zone it can be found, that the registered failure loads adjusted to a reference density of $\rho_{\text {mean }}=435 \mathrm{~kg} /$ $\mathrm{m}^{3}$ by $\left(\rho_{i} / 435\right)^{0.25}$ are almost directly proportional $\left(R^{2}=0.95\right)$ to the surface area of the effective anchoring zone given by $A_{\mathrm{g}}=\ell \pi d_{\mathrm{h}}$ (Fig. 8). A power approach:

$F_{\mathrm{ax}, 90, D}=k_{1} \cdot A_{\mathrm{g}}^{k_{2}}$

with $k_{1} \approx 0.044$ and $k_{2} \approx 0.8$ fits the data in a similar way $\left(R^{2}=0.96\right)$.

Except for the M16-high density series it can be seen, that in case of identical surface areas $A_{\mathrm{g}}$ but different rod diameters $d$ the rod with bigger diameter achieved higher pull-out strengths (Fig. 9).

As already mentioned before, the tests were planned to follow a certain range of geometrical proportions in terms of drill-hole diameter $d_{\mathrm{h}}$ and anchoring length $\ell$, represented by the parameter $\lambda=\ell / d_{\mathrm{h}}$. The test set-up with all rods of identical diameter glued into the same glulam beam (Fig. 4) enabled a good comparison of the strength performance in particular as a function of the glued length and $\lambda$. The M12 series were

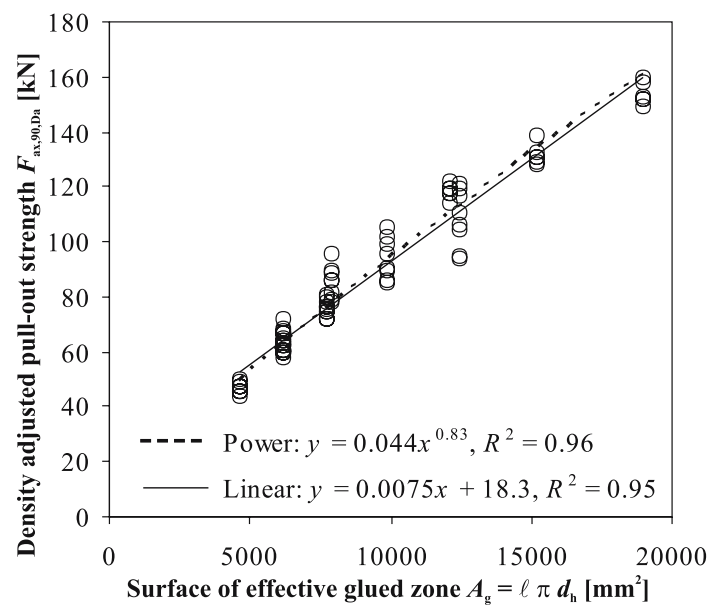

Fig. 8 Density adjusted pull-out strength of all specimens versus surface area of the effective glued zone

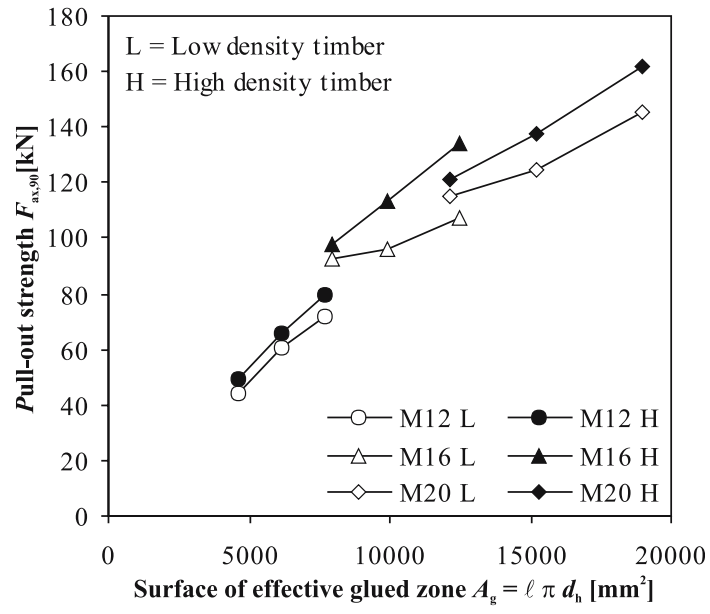

Fig. 9 Mean pull-out strength versus surface area of drillhole grouped according to diameter and wood density

conducted in two sets with the rods being set in different glulam samples. This was considered by splitting up the results for this analysis. Besides analysing the test results with regard to $\lambda$ (Fig. 10), the influences of the single parameters $\ell$ and $d_{\mathrm{h}}$ were studied, in order to get an idea on their power. The nominal shear strength $\tau_{\text {ax,mean }}$ was calculated assuming a constant distribution over the anchoring length $\ell$. On this base the mean shear stress in the wood-adhesive interface varied between $12.3 \mathrm{~N} / \mathrm{mm}^{2}$ for Series M16H$\lambda=7.8$ and $7.7 \mathrm{~N} / \mathrm{mm}^{2}$ for Series M20L- $\lambda=12.5$.

In general it can be observed that mean ultimate shear stress decreases with increasing length and increasing slenderness of the glued zone.

Except the M12-series of set 1 (M12L-1 and $\mathrm{M} 12 \mathrm{H}-1)$ the progression of all other results shows a good correspondence to a $\lambda^{-1 / 3}$ - or a $\ell^{-1 / 3}$. line, respectively.

However, based on our test results an influence of the drill-hole diameter on the nominal shear strength could not be verified.

\section{Design approaches versus test results}

\subsection{Design model by Riberholt (1988)}

According to Riberholt [11] the pull-out strength of axially loaded glued bolts set in Norway Spruce 


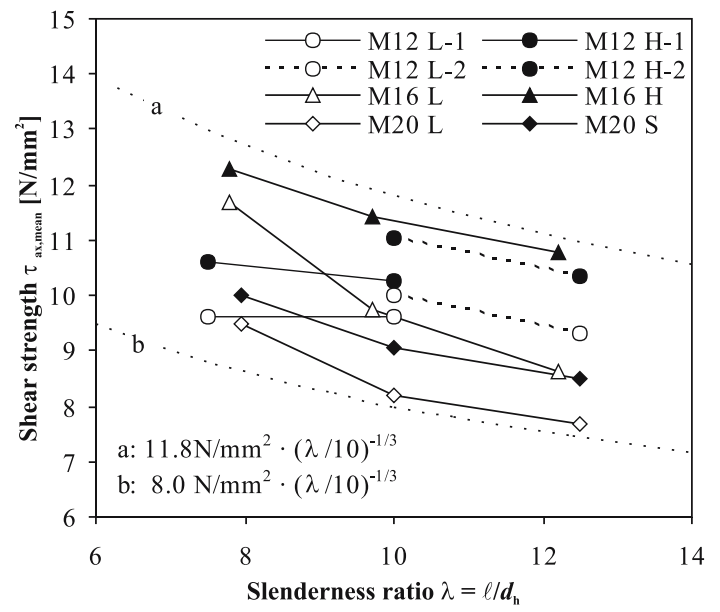

Fig. 10 Influence of slenderness ratio: test results together with plotted $\lambda^{-1 / 3}$ lines

glulam parallel or perpendicular to the grain can be estimated by

$F_{\text {ax,estim }}[N]=f_{\text {ws }} \cdot \rho \cdot d \cdot \sqrt{\ell_{\mathrm{g}}}$ for $\ell_{\mathrm{g}} \geq 200 \mathrm{~mm}$

$F_{\text {ax,estim }}[N]=f_{\mathrm{w} \ell} \cdot \rho \cdot d \cdot \ell_{\mathrm{g}} \quad$ for $\ell_{\mathrm{g}}<200 \mathrm{~mm}$

where $\rho=$ density $\left(\mathrm{g} / \mathrm{cm}^{3}\right), d=\max$ (hole diameter; outer bolt diameter) $(\mathrm{mm}), \ell_{\mathrm{g}}=$ glued length $(\mathrm{mm})$ and $f_{\mathrm{w} s}, f_{\mathrm{w} \ell}=$ withdrawal parameters.

The Eqs. 2 and 3 can be used to perform calculations both on the mean and on the characteristic level. When calculating the mean pullout strength, the density $\rho$ has to be assigned a socalled specific value, (which refers to the oven dry mass but to the volume in humid condition, i.e. $\approx 12 \%$ ) and the mean values of the withdrawal parameters $f_{\mathrm{w} s}$ and $f_{\mathrm{w} \ell}$ for Araldit have to be taken as

$f_{\mathrm{ws}, \text { mean }}=650 \mathrm{~N} / \mathrm{mm}^{1.5} \quad f_{\mathrm{w} \ell \text {, mean }}=46 \mathrm{~N} / \mathrm{mm}^{2}$

Pull-out strength calculations on the characteristic level (5th percentile) are based on the characteristic values of the withdrawal parameters $f_{\mathrm{w} s}$ and $f_{w \ell}$ :

$f_{\mathrm{ws}, k}=627 \mathrm{~N} / \mathrm{mm}^{1.5} \quad f_{\mathrm{w} \ell, k}=44.3 \mathrm{~N} / \mathrm{mm}^{2}$

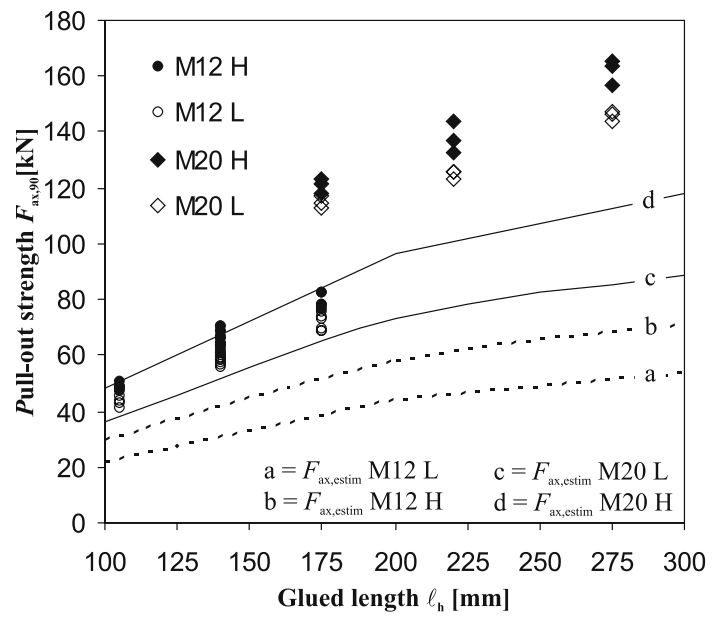

Fig. 11 Test results compared to the design approach by Riberholt [11]

and the density $\rho$ has to be assigned its characteristic value (5th percentile) $\rho_{k}$.

Figure 11 shows all test results in comparison to the Riberholt model on the mean level. The model is calculated only for the biggest diameter M20 and for the smallest diameter M12. All other design predictions progress between these two curves. The pull-out strength values derived from the tests considerably exceed the mean values of the model. The influence of density on the pull-out strength on base of the tests was observed to be smaller than predicted by the model.

\subsection{Design approach by Bernasconi (2001)}

Based on about 200 experimental pull-out test results with glued laminated Spruce timber from a normal production, hole diameters $d_{\mathrm{h}}$ varying from 12 to $30 \mathrm{~mm}$, anchoring lengths between 50 and $350 \mathrm{~mm}$ and wood densities from 390 to $550 \mathrm{~kg} / \mathrm{m}^{3}$, Bernasconi [17] suggested a design model. The variation of the strength was found to be proportional to the diameter of the hole with an exponent of -0.5 , whereas a variation of the strength depending on the anchoring length was not given. In case of timber failure the following rule for the calculation of the pull-out strength of glued-in rods perpendicular to the grain may be applied: 
$\tau_{k}=25 \cdot d_{\mathrm{h}}^{-0.5}($ characteristic value $)$

$\tau_{\text {mean }}=32 \cdot d_{\mathrm{h}}^{-0.5}($ mean value $)$

Figure 12 shows this approach together with all test results. In comparison to our results the design approach is quite conservative but the progression of the design curve follows our minimum observed strengths very well. However, in particular the big scatter of the M16 shear strengths $\left(d_{\mathrm{h}}=18 \mathrm{~mm}\right)$ doesn't permit that the progression of the observed mean strengths also follows the respective model prediction.

According to Bernasconi [16] the influence of wood density is said to be non-existent: A statistical analysis of Bernasconis test results showed a very poor correlation between density and strength. In cases where it is possible to describe a trend for a relation between density and strength, Bernasconi suggests to account for this influence by $\rho^{c}$, with $c=0$ to 0.3 . These values can be confirmed by our tests (see Sect. 3.2).

\subsection{GIROD approach (2001)}

The results of an extensive European research project on glued-in rods called GIROD is presented in [9]. The GIROD approach [9] is based on 1D shear lag theory by Volkersen [18-21] and

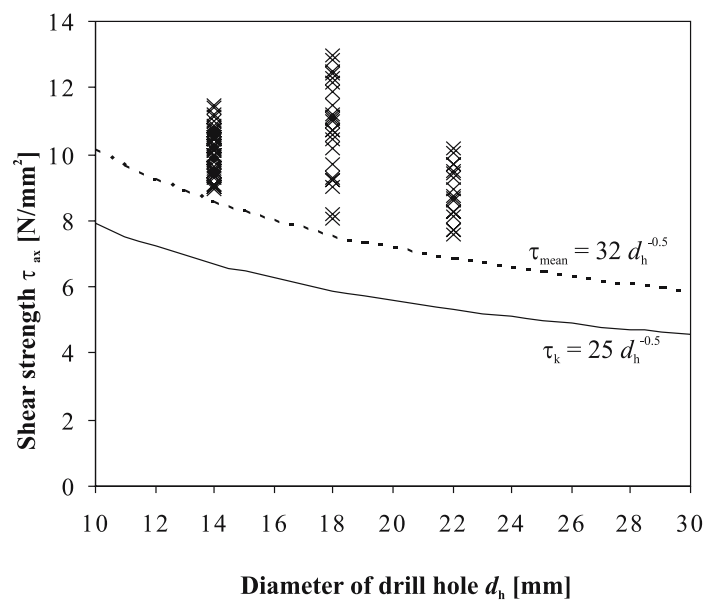

Fig. 12 Test results compared to a design approach by Bernasconi [17] quasi-nonlinear fracture mechanics [22]. It uses the following definitions:

$\varpi=\sqrt{\frac{\ell_{\mathrm{geo}}}{\ell_{\mathrm{m}}}}$

$\ell_{\mathrm{geo}}=\frac{\pi \cdot d \cdot \ell^{2}}{2 \cdot A_{r}} \cdot(1+k)$

$\ell_{\mathrm{m}}=\frac{E_{\mathrm{r}} \cdot G_{\mathrm{f}}}{\tau_{\mathrm{f}}^{2}}$

$k=\frac{E_{\mathrm{r}} \cdot A_{\mathrm{r}}}{E_{\mathrm{w}} \cdot A_{\mathrm{W}}}$

$A_{\mathrm{r}}=\pi \cdot\left(\frac{d_{\mathrm{nom}}}{2}\right)^{2}$

$d_{\text {nom }}=d$

where $E_{\mathrm{r}}=$ MOE of steel $\operatorname{rod}\left(\mathrm{N} / \mathrm{mm}^{2}\right), E_{\mathrm{w}}=$ MOE of wood (in direction of $\mathrm{rod})\left(\mathrm{N} / \mathrm{mm}^{2}\right)$, $A_{\mathrm{r}}=$ cross-section area of the rod $\left[\mathrm{mm}^{2}\right]$, $A_{\mathrm{w}}=$ cross-section area of the wood $\left(\mathrm{mm}^{2}\right)$, $\ell=$ glued length $(\mathrm{mm}), d=$ diameter of the $\operatorname{rod}$ $(\mathrm{mm}), G_{\mathrm{f}}=$ fracture energy $\left(\mathrm{N} \mathrm{mm} / \mathrm{mm}^{2}\right)$ and $\tau_{\mathrm{f}}=$ local shear strength $\left(\mathrm{N} / \mathrm{mm}^{2}\right)$.

For a pull-distributed (PD) loading the crosssection area of wood $A_{\mathrm{w}}$ might be set equal $4 a^{2}$ where $a$ is twice the distance from the centre of the rod to the closest edge of the timber crosssection [9]. It was assumed that the pull pile foundation loading (PF) used in our tests generates a constant volume load on the wood in this section which is a basic parameter for the application of the PD loading model used in GIROD. On this base the ratio between shear stress at failure level evenly distributed over the surface area of the glued zone and the local bond line strength $\tau_{f}$ can be expressed as follows:

$\frac{F_{\mathrm{ax}}}{\tau_{\mathrm{f}} \cdot \pi \cdot d \cdot \ell}=\frac{1+k}{\varpi / \tanh (\varpi)+k}$ 
The GIROD model was verified by tests on glulam produced from grade $\mathrm{C} 35$ or better timber lamellas [9] which have similar properties as the timber used for our high-density samples.

In Fig. 13 our test results of all high-density samples are compared with the GIROD model. The GIROD curves were calculated on base of Eq. 12 which delivers mean strength values on base of the following parameters [9]:

$$
E_{\mathrm{r}}=200,000 \mathrm{~N} / \mathrm{mm}^{2} \quad E_{\mathrm{w}, 90}=430 \mathrm{~N} / \mathrm{mm}^{2}(\mathrm{C} 35)
$$

$\tau_{\mathrm{f}}=10.5 \mathrm{~N} / \mathrm{mm}^{2} \quad G_{\mathrm{f}}=1.9 \mathrm{~N} \mathrm{~mm} / \mathrm{mm}^{2}$

In the section of $\varpi$ values according to the geometries used in our tests, the GIROD design prediction (line "a") progresses almost linear. Line "a" represents M20 rods, however, predictions on base of M16 and M12 rods progress almost identical as the $A_{\mathrm{r}} / A_{\mathrm{w}}$ ratios of our specimens were similar. Being aware of the fact, that the GIROD approach reflects the mean level, the test results are considerably higher than the prediction by the model. This also implies that $\tau_{\mathrm{f}}$ and $G_{\mathrm{f}}$ for our test results can be set higher. Line " $b$ " in Fig. 13 indicates a prediction on base of Eq. 12 adapted to the mean level of the observed shear strengths with a resulting $\tau_{\mathrm{f}}=13.2 \mathrm{~N} / \mathrm{mm}^{2}$. However, our test set-up did not permit to determine $\tau_{\mathrm{f}}$ and $G_{\mathrm{f}}$ on base of

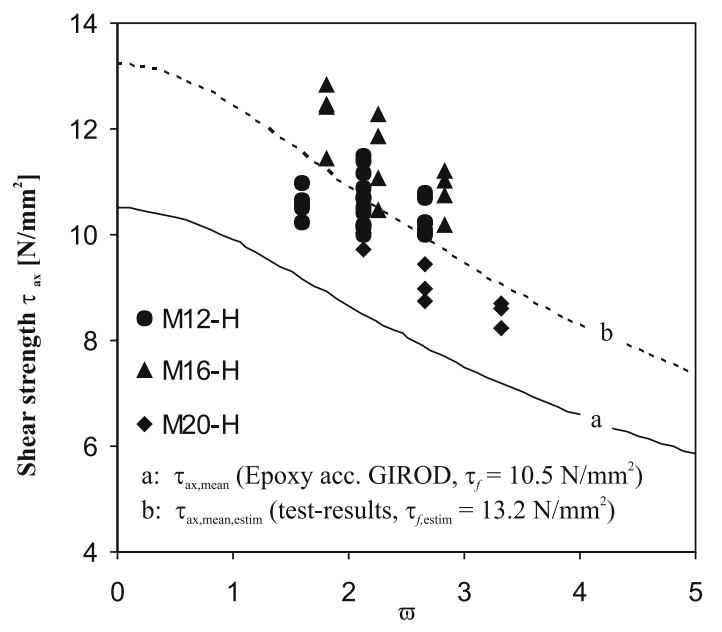

Fig. 13 Test results compared to the GIROD design approach [9] for loading case PD measurements. Therefore, the presented progression of the strength prediction (line "b") as well as the mentioned $\tau_{f}$ should only be regarded as estimation for analysing our test data with the GIROD model.

\subsection{DIN 1052:2004 design model}

According to the German design code DIN 1052:2004-08 [23] the characteristic value for axially loaded rods glued-in parallel or perpendicular to the grain may in case of bond line failure be derived from:

$R_{\mathrm{ax}, k}=\pi \cdot d \cdot \ell_{\mathrm{ad}} \cdot f_{k 1, k}$

where $d=$ diameter of the $\operatorname{rod}(\mathrm{mm}), \ell_{\mathrm{ad}}=$ glued length $(\mathrm{mm})$ and $f_{k 1, k}=$ characteristic value of bond line strength $\left(\mathrm{N} / \mathrm{mm}^{2}\right)$.

The characteristic value of the bond line strength $\mathrm{f}_{k 1, k}\left(\mathrm{~N} / \mathrm{mm}^{2}\right)$ depends on the glued length:

$f_{k 1, k}=5.25-0.005 \cdot \ell_{\mathrm{ad}} \quad$ if $250<\ell_{\mathrm{ad}} \leq 500 \mathrm{~mm}$

$f_{k 1, k}=5.25-0.005 \cdot \ell_{\mathrm{ad}} \quad$ if $250<\ell_{\mathrm{ad}} \leq 500 \mathrm{~mm}$

This bilinear design model is based on tests by Blass et al. [24] and is closely related to the Eqs. 2 and 3 by Riberholt [11]. According to the DIN model the pull-out strength does not depend on the wood density. The geometric parameters diameter $d$ and glued length $\ell$ are treated linearly. For an anchoring length longer than $250 \mathrm{~mm}$ the bond line strength has to be reduced with respect to $\ell$.

In Fig. 14 the test results are compared to the DIN model, which has been transferred to a shear stress formulation:

$\tau_{\mathrm{ax}, k}=\frac{R_{\mathrm{ax}, k}}{\pi \cdot d \cdot \ell_{\mathrm{ad}}}=f_{k 1, k}$

The pull-out strength values derived from the tests considerably exceed the characteristic values. A reduction of strength values is noticeable for a glued length longer than approximately 


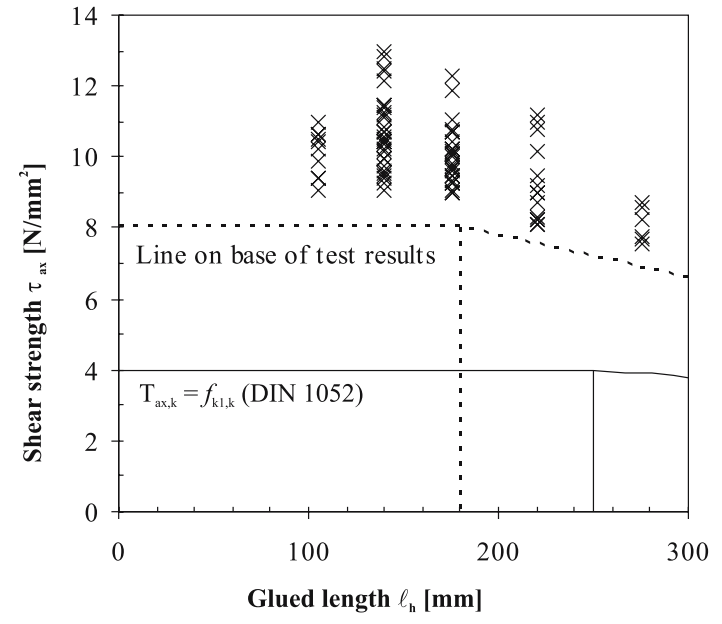

Fig. 14 Test results compared to the DIN 1052 design approach [23]

$180 \mathrm{~mm}$. This result is close to Riberholt's approach presented in Sect. 4.1 (see above).

\subsection{Estimation of pull-out strength based on our tests}

Based on the test results presented in this paper, an approach to estimate the mean pull-out strength based on the surface area of the glued zone can be suggested (Eq. 17). This estimation is valid in particular for the $\mathrm{GSA}^{\circledR}$ system used in this study, which is in contrast to other systems characterized by shifting the anchorage zone to the inner part of structural timber:

$F_{\mathrm{ax}, 90, \text { mean }}=k_{1} \cdot A_{\mathrm{g}}^{k_{2}}(\mathrm{kN})$

where $A_{\mathrm{g}}=\ell \cdot \pi \cdot d_{\mathrm{h}}\left(\mathrm{mm}^{2}\right), \quad \ell=$ glued length $(\mathrm{mm})$ and $d_{\mathrm{h}}=$ diameter of the drill-hole $(\mathrm{mm})$.

In case of rods with metric threads M12, M16 and M20 and slenderness ratios of 7.5 to 12.5 bonded in Norway Spruce glulam with oven-dry density between 350 and $500 \mathrm{~kg} / \mathrm{m}^{3}$ factors $k_{1}$ and $k_{2}$ can be taken as: $k_{1}=0.045$ and $k_{2}=0.8$. A comparison of the test results with this approach is given in Fig. 8 .

\section{Conclusions}

Based on the test results it can be stated, that for the used GSA ${ }^{\circledR}$-system in case of rods bonded in
Norway spruce glulam perpendicular to the grain with a shift of the anchorage zone to the inner part of the timber:

- The pull-out strength is influenced by the wood density. This influence is less pronounced compared to rods set parallel to the grain. Design approaches therefore should neglect the density influence or account for it carefully, e.g. by using an exponent of $c_{90}=0.25$.

- The evaluated design models tend to (partly considerably) underestimate the capacity of glued-in rod connections with shifted anchorage zones assessed in this study. Models could principally be based on the surface area of the anchoring zone $A_{\mathrm{g}}\left(\mathrm{mm}^{2}\right)$ and on the shear strength of the adhesive-wood interface. For rods with metric thread M12, M16 and M20 and slenderness ratios of 7.5 to 12.5 bonded in Norway Spruce glulam with oven-dry densities between 350 and $500 \mathrm{~kg} / \mathrm{m}^{3}$, the following approach to estimate the pull-out strength is suggested: $F_{\mathrm{ax}, 90, \text { mean }}=0.045 \cdot A_{\mathrm{g}}^{0.8}$

- Compared to rods of the same diameter and anchoring length set parallel to the grain [12] the pull-out strengths of rods bonded in glulam perpendicular to the grain were 20$50 \%$ higher.

- The influence of the anchoring length and the slenderness ratio on the nominal shear strength $f_{v, 90 \text {,mean }}$ can be accounted for by $\ell^{-}$ $1 / 3$ and $\lambda^{-1 / 3}$, respectively.

Acknowledgements The presented work was funded partly by the Swiss State Secretariat for Education and Research SER within the framework of COST Action E34 'Bonding of Timber'. The assistance of T. Strahm (sample logistics) and $\mathrm{K}$. Weiss (mechanical testing) is gratefully acknowledged.

\section{References}

1. Madsen B (1992) Structural behaviour of timber. Timber Engineering Ltd., Vancouver, Canada

2. Madsen B (2000) Behaviour of timber connections. Timber Engineering Ltd., Vancouver, Canada

3. Kangas J (1994) Joints of glulam structures based on glued-in ribbed steel rods. VTT Publication 196, VTT

4. Gaunt D (1999) Joints in glulam using groups of epoxy-grouted steel bars. NZ Timber Des J 26(1): 34-38 
5. Kuhlmann U, Aicher S, Lippert P (2001) Rigid frame corners with glued-in rods. International RILEM symposium on joints in timber structures, Stuttgart, Germany, pp 343-352

6. Buchanan AH, Moss PJ, Townsend PK (1990) Reinforcing bars epoxy bonded in glue laminated timber. International timber engineering conference, Tokyo, pp 601-610

7. Gerold M (1993) Anwendung von in Holz eingebrachten, in Schaftrichtung beanspruchten Gewindestangen aus Stahl. Bautechnik 70(10):603-613

8. Aicher S, Gustafsson PJ, Wolf M (1999) Load displacement and bond strength of glued-in rods in timber influenced by adhesive, wood density, rod slenderness and diameter. International RILEM symposium on timber engineering, Stockolm, Sweden, p 10

9. Gustafsson P-J, Serrano E, Aicher S, Johansson C-J (2001) A strength design equation for glued-in rods. International RILEM symposium on joints in timber structures, Stuttgart, Germany, pp 323-332

10. Möhler K, Siebert W (1981) Eingeleimte Gewindestangen. Holzbau-Statik-Aktuell 6:4-6

11. Riberholt H (1988) CIB-W18/21-7-2: Glued bolts in glulam-Proposal for CIB code. Meeting twenty-one, Parksville, Vancouver Island, Canada, p 18

12. Steiger R, Gehri E, Widmann R (2006) Pull-out strength of axially loaded steel rods bonded in glulam parallel to the grain. Materials and Structures (published online)

13. Strahm T (2000) Das entwurfsfreundliche und leistungsfähige GSA-Ankersystem. 32. SAHFortbildungskurs Verbindungstechnik im Holzbau, Weinfelden, Schweiz, pp 165-169

14. Fabris A (2001) Verbesserung der Zugeigenschaften von Bauholz parallel zur Faser mittels Verbund mit profilierten Stahlstangen, Dissertation ETH Nr. 14050, ETH Zürich, Professur für Holztechnologie
15. Blass HJ, Laskewitz B (2001) Load-carrying capacity of axially loaded rods glued-in perpendicular to the grain. International RILEM symposium on joints in timber structures, Stuttgart, Germany, pp 363-371

16. Bernasconi A (2001) CIB-W18/34-7-6: behaviour of axially loaded glued-in rods-requirements and resistance, especially for spruce timber perpendicular to the grain direction. Meeting thirty-four, Venice, Italy, p 11

17. Bernasconi A (2001) Axially loaded glued-in rods for high capacity joints-behaviour and resistance. International RILEM symposium on joints in timber structures, Stuttgart, Germany, pp 373-381

18. Volkersen O (1938) Die Nietkraftverteilung in zugbeanspruchten Nietverbindungen mit konstanten Laschenquerschnitten. Luftfahrtforschung 15 (Lfg. 1/ 2):41-47

19. Volkersen O (1953) Die Schubkraftverteilung in Leim-, Niet- und Bolzenverbindungen, Teil 1. Energie und Technik 5(3):68-71

20. Volkersen O (1953) Die Schubkraftverteilung in Leim-, Niet- und Bolzenverbindungen, Teil 2. Energie und Technik 5(5):103-108

21. Volkersen O (1953) Die Schubkraftverteilung in Leim-, Niet- und Bolzenverbindungen, Teil 3. Energie und Technik 5(7):150-154

22. Gustafsson PJ (1987) CIB-W18/20-18-2: analysis of generalized Volkersen joints in terms of non linear fracture mechanics. Meeting twenty, Dublin, Ireland, p 16

23. DIN (2004) DIN Deutsches Institut für Normung e.V. Entwurf, Berechnung und Bemessung von Holzbauwerken, p 193

24. Blass HJ, Eberhart O, Ehlbeck J, Gerold M (1996) Wirkungsweise von eingeleimten Gewindestangen bei der Aufnahme von Querzugkräften in gekrümmten Biegeträgern und Entwicklung von Bemes sungsgrundlagen, Teil 3, Versuchsanstalt für Stahl, Holz und Steine. Universität Karlsruhe 